\title{
RELIGIUSITAS, LINGKUNGAN DAN PEMBELIAN GREEN PRODUCT PADA KONSUMEN GENERASI Z
}

\author{
Fani Firmansyah, Puji Endah Purnamasari, Muhammad Djakfar \\ Fakultas Ekonomi, Universitas Islam Negeri Maulana Malik Ibrahim \\ Malang firmansyahfani@yahoo.co.id
}

\begin{abstract}
The formation of consumers attitude will be shape a person intention to do or not and also intention will influence the formation of consumer behaviour. The purpose of this research is to fill the gap with the previous research by investigating the role of religiosity, as an essential part of a person belief, in the relationship between environmental variable and the intention to purchase green products or environmental friendly product. Questionnaire or pre-test testingwas carried out by quesionare to students of State Universities in Malang in more significant numbers to obtain primary data. Analyzed by Moderated Regression Analysis. The result of this research indicated that religiosity is related to spiritual values that influence one's actions in making decisions. Religiosity is very important in one's life. So that generation $Z$ who has high level of religiosity will think of the environmental for the actions they do during the purchase activity. Thus generation $Z$ will choose environmentally friendly products (green products) so that the surrounding environment is safe and avoid environmental damage.
\end{abstract}

Keywords: religiosity, environment, green product

\section{Cara mencitasi:}

Firmansyah, F., Purnamasari, P.E., Djakfar, M. (2019). Religiusitas, Lingkungan dan Pembelian Green Product pada Konsumen Generasi Z. Iqtishoduna: Jurnal Ekonomi Dan Bisnis Islam. Vol 15 (1): 57-70.

\section{Pendahuluan}

Beberapa tahun terakhir ini, isu isu lingkungan merupakan salah satu isu yang urgent dalam hubungannya antara produsen serta konsumen. Dalam aktivitas bisnis yang harus dilakukan adalah dengan tidak mengabaikan lingkungan sekitar kita yang dapat dilakukan melalui kegiatan strategi pemasaran dengan jalan memproduksi dan menggunakan produk yang ramah lingkungan (Cronin et al, 2011). Perilaku konsumen dalam aktivitas pemasaran adalah hal yang penting dan merupakan hal yang harus diperhatikan . Suatu produk dapat diminati oleh konsumen harus memiliki nilai lebih berupa consumption value. Dalam memilih produk, keputusan 
Fani Firmansyah, Puji Endah Purnamasari, Muhammad Djakfar

konsumen akan dipengaruhi oleh: nilai fungsional, sosial, emosional, epistemic dan kondisional (Shimp, 2000).

Penelitian Ko and Byoungho (2017) menemukan pengaruh variabel budaya dapat mempengaruhi perilaku konsumen yang sadar akan pengaruh lingkungan. Budaya dapat dikatakan sebagai isu utama dalam penelitian dalam perilaku konsumen serta keputusan pembelian. Beberapa penelitian mengidentifikasi budaya sebagai faktor dari luar (eksternal) yang mampu membentuk perilaku konsumsi seorang individu.

Selain budaya, religiusitas juga mempunyai peranan yang penting dalam pengambilan keputusan sehari hari. Religiusitas itu mempengaruhi cara orang hidup, pilihan yang mereka buat, apa yang mereka makan dan dengan siapa mereka bergaul (Rahman et al., 2016). Pilihan konsumsi seorang konsumen dapat dipenagruhi oleh variabel religiusitas dan mampu membentuk nilai dan sikap (Islam \& Chandrasekaran, 2016).

Religiusitas adalah salah satu faktor yang dapat menentukan konsumsi prosuk oleh konsumen. Pentingnya nilai nilai religious yang dapat digunakan sebagai pedoman di dalam keputusan pembelian produk yang ramah lingkungan senada dengan penelitian Hassan (2014). Maineri et al. (1997) mengungkapkan nilai ternyata mampu meningkatkan serta mempengaruhi perilaku. Walaupun religiusitas merupakan sesuatu hal yang sangat pribadi, namun konsumsi pada produk ramah lingkungan juga sangat berhubungan nilai, etika serta moral.

Setiap muslim diwajibkan untuk melindungi bumi dan sekitarnya. Segala tindakan yang dilakukan dengan sengaja serta berdampak kepada lingkungan serta sumber daya alam sangat tidak dianjurkan dalam Islam. Manusia diciptakan di muka bumi untuk menjadi khalifah dengan tanggung jawab besar menjaga dan merawat lingkungan (Djakfar, 2007).

Tenaga pemasaran saat ini dituntut untuk berinovasi serta menemukan strategi baru untuk dapat mengembangkan produk ramah lingkungan. Saat ini, beberapa perusahaan mulai memproduksi produk dengan melakukan stratgei perusahaan menuju green marketing (Saputra, 2013). Saat ini, green marketing telah banyak dilakukan secara global dimana mereka menawarkan berbagai jenis produk yang ramah terhadap lingkungan. Keputusan dalam pembelian produk yang ramah terhadap lingkungan merupakan kesadaran serta pertimbangan akan pentingnya menjaga lingkungan Gurau dan Ranchhod (2005).

Hal tersebut menuntut produsen untuk dapat memproduksi produk yang tidak saja menguntungkan secara ekonomis namun juga harus dapat ikut serta menjaga lingkungan. Proses produksi, penelitian, pengolahan, 
Religiusitas, Lingkungan dan Pembelian Green Product...

pembuangan dan pengolahan limbah serta pendistribusian produk harus dapat menjaga kelestarian lingkungan. Aktivitas ini disebut sebagai green productivity. Produk yang dihasilkan dikenal dengan istilah green product. Green product adalah produk ramah lingkungan yang diproses dan manfaat yang dihasilan dapat mengurangi dampak kerusakan lingkungan.

Saat ini, isu lingkungan dan kepedulian konsumen terhadap lingkungan saat ini menjadi sangat penting bagi tenaga pemasaran serta para pembuat kebijakan dimana kegiatan yang dilakukan akan mengubah perilaku konsumen untuk lebih perduli terhadap lingkungan namun juga sebagai strategi dalam aspek tanggungjawab sosial perusahaan dan lingkungan (Buttler, 2013). Aplikasi tanggungjawab sosial merupakan sebuah kewajiban bukan merupakan suatu pilihan (Charter et al., 2002).

Ali dan Ahmad (2013) mengemukakan bahwa perilaku lingkungan dapat dicirikan melalui sikap dan aksi untuk melingdungi lingkungan sekitarnya. Sikap (attitudes) konsumen merupakan faktor yang penting yang dapat mempengaruhi keputusan konsumen untuk memutuskan melakukan pembelian produk (Oliver, 2010). Sikap konsumen dapat membentuk niat konsumen untuk dapat melakukan suatu tindakan serta niat melakukan pembelan akan mempengaruhi perilaku konsumen. Al Bayrak et al. (2013) menunjukkan bahwa jika konsumen memiliki sikap yang positif terhadap isu lingkungan, maka dapat dikatakan bahwa konsumen tersebut memiliki niat untuk membeli produk ramah lingkungan yang dapat dikatakan pula ikut serta dalam pelestarian alam.

Agama adalah merupakan nilai utama yang mampu mempengaruhi sikap dan perilaku (Cornwell et al., 2005). Penelitian ini akan menguji pengaruh religiusitas pada sikap pembentukan dan keputusan pembelian produk ramah lingkungan. Penelitian ini dapat digunakan sebagai titik awal untuk dapat memahami pengaruh religiusitas sebagai jalan hidup kearah yang lebih baik di masa sekarang dan masa yang akan datang serta berdampak baik bagi lingkungan serta melihat seberapa besar penting dan pengaruh variabel religiusitas pada kehidupan seorang muslim dalam keputusan pembelian produk ramah lingkungan.

\section{Kajian Pustaka \\ Religiusitas}

Eid \& El Gohary (2014) dalam penelitiannya mengemukakan bahwa religiusitas berbeda makna dengan agama (Religion). Religiusitas dapat dimaknai sebagai sesuatu hal yang berhubungan erat dengan pengalaman individu, kepercayaan individu serta ritual-ritual agama. Membangun 
Fani Firmansyah, Puji Endah Purnamasari, Muhammad Djakfar

religiusitas merupakan hal yang sangat penting yang dapat mempengaruhi keputusan pembelian konsumen secara kognifit. Alam et al. (2011) mengungkapkan bahwa konsep religiusitas dapat dimasukkan sebagai salah satu dari strategi marketing karena religiusitas memiliki pengaruh kepada perilaku pembelian konsumen. Religiusitas dalam hubungannya dengan perilaku konsumen tergantung pada seberapa besar komitmen individu karena agama merupakan sesuatu hal yang sangat personal (Muhamad et al., 2016).

\section{Hubungan Religiusitas dengan Perilaku Pembelian}

Beberapa penelitian banyak yang meneliti hubungan antara budaya serta perilaku konsumen. Namun hanya adana sedikit penelitian yang memasukkan aspek agama sebagai nilai dalam individu yang dapat memberikan pengaruh terhadap keputusan pembelian. Menurut Mokhlis (2009) diyakini bahwa agama mampu mempengaruhi kehidupan sehari hari mereka serta sikapnya pada keputusan pembelian. Agama melarang kita untuk menggunakan barang dan jasa tertentu. Misalnya, minuman keras. Aspek aspek dalam agama membuktikan bahwa nilai nilai tersebut dapat membentuk emosional individu, kesejahteran psilologi dan nantinya akan mampu memberikan pengaruh pada pilihan mereka dalam melakukan konsumsi. Bhuian and Sujeet (2017) menemukan religiusitas dapat mempengaruhi gaya hidup dan perilaku konsumen yang dapat menentukan pilihan produk yang digunakan.

\section{Green Products}

Green product merupakan produk yang tidak menyebabkan polusi dan tidak merusak lingkungan dan sumber daya alam. Green product merupakan produk yang dapat didau ulang (Shamdasami et al., 1993). Wasik (1996) mendefinisikan sebagai produk yang baik dalam isi maupun kemasannya dapat mengurangi dampak lingkungan. dapat dikatakan bahwa Green product merupakan suatu produk yang mengkombinasikan strategi daur ulang serta tidak mengandung bahan yang beracun (Chen \& Chai, 2010).

\section{Sikap terhadap Lingkungan}

Sikap merupakan perasaan, penilaian serta kecenderungan yang konsisten atas objek atau gagasan (Kotler, 2000). Sikap dapat merefleksikan kesukaan maupun ketidaksukaan seseorang terhadap sebuah obyek.

\section{Pengetahuan terhadap Lingkungan}

Pengetahuan lingkungan menurut Fryxell \& Lo dalam Ashary et al. (2018) merupakan suatu pengetahuan tentang hubungan dan konsep tentang lingkungan dan ekosistemnya. Pengetahuan tentang lingkungan dapat digambarkan sebagai apa yang diketahui oleh manusia tentang lingkungan 
Religiusitas, Lingkungan dan Pembelian Green Product...

sekitarnya. Pengetahuan terhadap lingkungan menurut Nugroho, Hariyanto, \& Suharini (2017) adalah kemampuan individu untuk dapat mengindentifikasi serta menentukan konsep yang berhubungan dengan lingkungan. Pengetahuan tentang lingkungan yang dimiliki oleh seorang individu tentang lingkungan. Jika konsumen memiliki pengetahuan tentang isu lingkungan dapat dikatakan bahwa mereka memiliki kesadaran untuk menggunakan produk hijau. D'Souza et al (2006) mengatakan bahwa pengetahuan lingkungan berkembang dalam dua bentuk, yaitu konsumen harus diajarkan untuk dapat memahami dampak dari produk terhadap lingkungan

\section{Niat untuk Melakukan Pembelian Green Product}

Kecenderungan seorang individu untuk membeli barang tertentu di masa yang akan datang merupakan pengertian dari niat pembelian. Niat melakukan pembelian adalah konsep yang penting di dalam pemasaran. Motivasi seseorang dalam usahanya untuk melakukan suatu tindakan merupakan definisi sikap yang memiliki konsep berbeda dengan niat. Niat melakukan pembelian mengarah pada tujuan serta kecenderungan seorang konsumen untuk membeli apa yang disukai dan diminati (Kotler \& AMstrong, 2008). Menurut Rashid (2009) Niat melakukan pembelian terhadap produk hijau merupakan persentase kemungkinan dan kesediaan seseorang untuk mempertimbangkan melakukan pembelian produk hijau sebagai keputusan pembeliannya.

\section{Kerangka Konsep dan Hipotesis Penelitian} berikut:

Kerangka konsep dalam penelitian ini dapat digambarkan sebagai

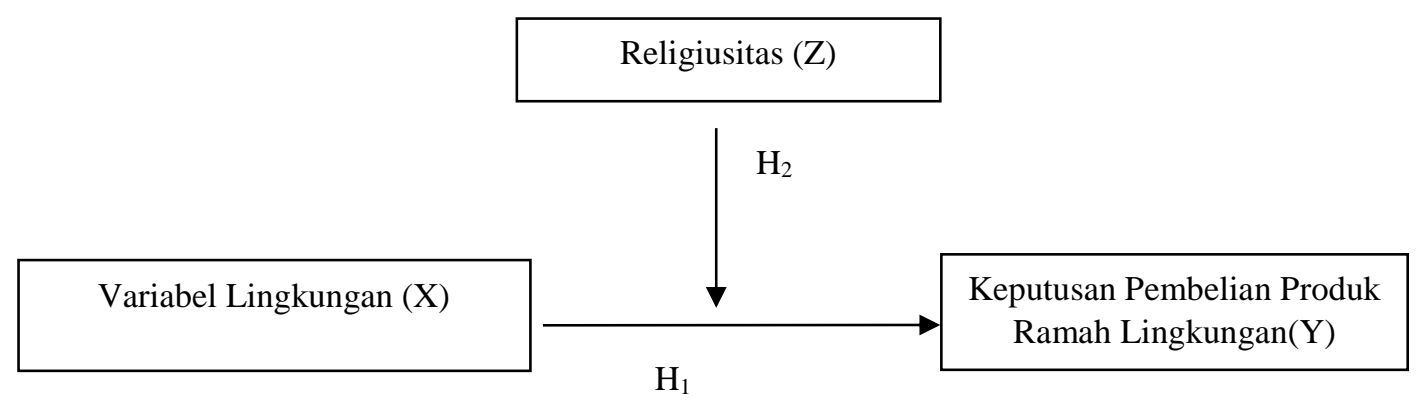

\section{Gambar 1. Kerangka Konsep Penelitian}

\section{Hipotesis Penelitian}

H1 : diduga terdapat pengaruh lingkungan terhadap keputusan pembelian produk ramah lingkungan 
Fani Firmansyah, Puji Endah Purnamasari, Muhammad Djakfar

H2 : diduga religiusitas dapat memperkuat hubungan lingkungan terhadap keputusan pembelian produk ramah lingkungan

\section{Metode}

\section{Desain Penelitian}

Penelitian ini dilakukan dengan menyebarkan kuesioner kepada mahasiswa Universitas Islam Negeri (UIN) Malang. Sebelum seluruh kuesioner disebarkan, maka penelitian melakukan pre test dengan menyebarkan 30 kuesioner pendahuluan. Setelah hasil pre test dilakukan pengujian serta terbukti valid serta reliable, maka kuesioner tersebut selanjutnya disebarkan kembali kepada responden dalam jumlah yang lebih besar yaitu 379 responden untuk mendapatkan data primer. Metode analisis data di dalam penelitian ini menggunakan moderated regression analysis.

\section{Hasil Penelitian}

Analisis Regresi Pengaruh Lingkungan (X) terhadap Keputusan Pembelian Produk Ramah Lingkungan

Tabel 1. Pengaruh Lingkungan (X) terhadap Keputusan Pembelian Produk Ramah Lingkungan

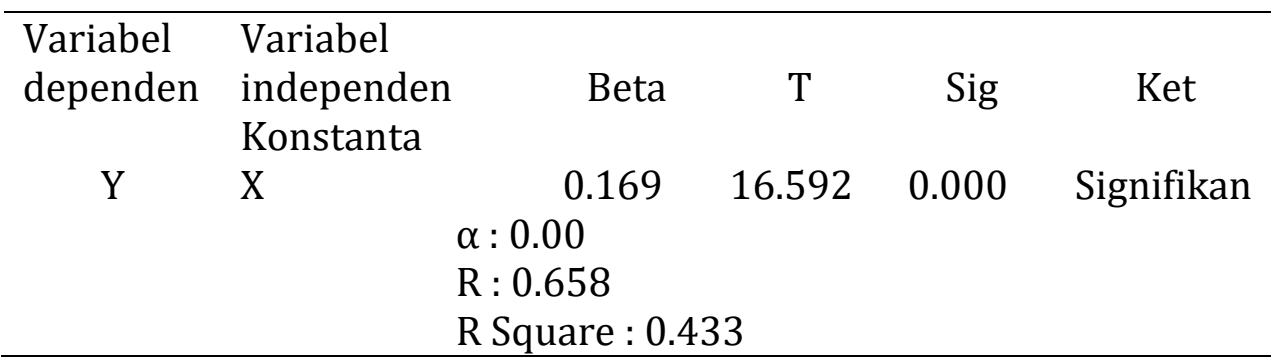

Hasil Pengujian Moderate Regression Anaysis

Tabel 2. Pengujian Moderate Regression Anaysis Model 1 dan Model

\begin{tabular}{llllll}
\hline $\begin{array}{l}\text { Variabel } \\
\text { terikat }\end{array}$ & $\begin{array}{l}\text { Variabel } \\
\text { Bebas }\end{array}$ & Beta & T & Signifikasi & Keterangan \\
& Konstanta & & & & \\
Y & $\mathrm{X}$ & 0.169 & 16.592 & 0.000 & Signifikan \\
Model 1 & $\alpha: 0.05$ & & & & \\
& R: $: 0.658$ & & & & \\
& R Square : 0.433 & & & \\
& t Hitung : 16.592 & & & \\
& Signifikasi $t: 0.000$ & & &
\end{tabular}


Religiusitas, Lingkungan dan Pembelian Green Product...

\begin{tabular}{|c|c|c|c|c|c|}
\hline $\begin{array}{l}\text { Variabel } \\
\text { terikat }\end{array}$ & $\begin{array}{l}\text { Variabel } \\
\text { Bebas } \\
\text { Konstanta }\end{array}$ & Beta & $\mathbf{T}$ & Signifikasi & Keterangan \\
\hline Y & $\mathrm{X}$ & .055 & 3.466 & .001 & Signifikan \\
\hline \multirow{6}{*}{$\begin{array}{l}\text { Model 2a } \\
\text { (Melibatkan } \\
\text { variabel } \\
\text { moderasi) }\end{array}$} & $\mathrm{Z}$ & .209 & 8.777 & .000 & Signifikan \\
\hline & $\alpha: 0.05$ & & & & \\
\hline & $\mathrm{R}: 0.727$ & & & & \\
\hline & R Square : 0 & .529 & & & \\
\hline & F Hitung : 2 & 11.180 & & & \\
\hline & Signifikasi F & $: 0.000$ & & & \\
\hline \multirow{3}{*}{$\begin{array}{l}\text { Variabel } \\
\text { terikat }\end{array}$} & Variabel & Beta & $\mathbf{T}$ & Signifikasi & Keterangan \\
\hline & Bebas & & & & \\
\hline & Konstanta & & & & \\
\hline Y & $\mathrm{X}$ & .154 & 3.867 & .000 & Signifikan \\
\hline \multirow[t]{2}{*}{ Model 3b } & $\mathrm{Z}$ & .342 & 6.282 & .000 & Signifikan \\
\hline & $\mathrm{XZ}$ & -.002 & -2.709 & .007 & Signifikan \\
\hline (Melibatkan & $\alpha: 0.05$ & & & & \\
\hline variabel & $\mathrm{R}: 0.734$ & & & & \\
\hline moderasi & R Square : 0 & .538 & & & \\
\hline dan & F Hitung : 1 & 45.607 & & & \\
\hline interaksi) & Signifikasi F & $: 0.000$ & & & \\
\hline
\end{tabular}

\section{Pembahasan}

Pengaruh Variabel Lingkungan terhadap Keputusan Pembelian Produk Ramah Lingkungan

Hasil penelitian menunjukkan bahwa variabel lingkungan berpengaruh secara positif terhadap keputusan pembelian produk ramah lingkungan. Hasil penelitian di lapangan konsisten dengan temuan penelitian dari Ashary et al. (2018)., Ottman et al. (2006)., Suki (2013)., Suki dan Norbayah (2015) bahwa pengetahuan tentang lingkungan berpengaruh signifikan terhadap keputusan pembelian.

Secara kenyataan di lapangan, kehidupan seorang individu erat kaitannya dengan kepribadian yang dimilikinya dalam kehidupan. Sebab totalitas dari sebuah individu dapat disebut sebagai sebuah kepribadian apabila secara keseluruhan sitem psikofisiknya meliputi pembawaan, minatbakat, kecakapan, dan ciri-ciri yang terdapat dalam dirinya khas untuk menyesuaikan diri terhadap lingkungannya. Sikap dan pengetahuan mengenai lingkungan memiliki peran penting bagi seorang konsumen dalam mengambil keputusan pembelian. sikap terhadap lingkungan sebagai suatu kecenderungan belajar untuk merespon secara konsisten dengan keuntungan ataupun kerugian yang berhubungan dengan lingkungan (Rosyid, 2009). 
Fani Firmansyah, Puji Endah Purnamasari, Muhammad Djakfar

Dengan melihat dari segi aspek keuntungan dan kerugian yang ditimbulkan dari lingkungan inilah sikap kesadaran akan lingkungan penting untuk diterapkan dalam mekanisme kehidupan.

Salah satu bentuk kepedulian terhadap lingkungan tercermin dari keputusan seorang konsumen dalam melakukan pembelian produk ramah lingkungan. Keputusan konsumen dalam menggunakan produk ramah lingkungan diawali oleh seberapa besar pengetahuan mereka tentang lingkungan. Afeksi ekologi menurut Chen \& Chai (2010) merupakan aspek pendorong konsumen melakukan pembelian produk ramah lingkungan. Semakin tinggi pengetahuan yang mereka miliki tentang lingkungan akan dapat meningkatkan kepedulian mereka terhadap lingkungan (Shamdasami et al., 1993).

Adanya hubungan secara langsung variabel lingkungan terhadap keputusan pembelian produk ramah lingkungan dapat diartikan sebagai sikap positif terhadap lingkungan, kepedulian terhadap lingkungan, persepi dalam menanggapi permasalahan lingkungan yang serius, rasa tanggung jawab terhadap lingkungan, motivasi dalam berperilaku terhadap lingkungan, dan pengaruh dari teman terhadap variabel lingkungan akan memberikan dampak yang positif terhadap keputusan pembelian produk ramah lingkungan. Nilai nilai yang akan diterima oleh para pelanggan adalah perbedaan antara total jumlah nilai dengan total jumlah biaya. Konsumen yang peduli dan merasakan kepuasan akan produk ramah lingkungan akan melakukan pengambilan keputusan dengan membeli produk ramah lingkungan dengan pertimbangan nilai kepuasan dan sebagai pelestarian lingkungan.

Konsumen yang sadar akan lingkungan merasa dirinya merupakan bagian dari lingkungan. Dalam hidup konsumen tersebut akan mengintegrasikan kehidupannya dengan mempertimbangkan keberlangsungan lingkungan (alam semesta). Sejalan dengan pengetahuannya terhadap berbagai hal-hal yang berhubungan dengan lingkungan alam semesta dan ekosistem sebagai dasar untuk mengambil sebuah tindakan dalam upaya perlindungan terhadap lingkungan. Pengetahuan akan lingkungan ini penting terhadap konsumen yaitu sebagai upaya memberikan pemahaman mengenai lingkungan. Pengetahuan akan lingkungan berkembang dalam dua bentuk menurut (D'Souza et al., 2006) yaitu konsumen yang harus dididik untuk mampu memahami dampak dari produk bagi lingkungan mereka serta pengetahuan mereka tentang produk yang diproduksi dengan cara yang ramah terhadap lingkungan.

Di dalam Islam, proses pengambilan keputusan sebaiknya dilakukan secara adil dan membawa kemaslahatan bagi umat. Dalam hal ini, konsumen 
Religiusitas, Lingkungan dan Pembelian Green Product...

dalam melakukan pembelian suatu produk harus pula memikirkan kemaslahatan lingkungan atas prosuk yang telah dikonsumsinya. Lingkungan harus dijaga kemaslahatannya dan jangan sampai di rusak keberadaannya. Peringatan dari Allah swt. terhadap hamba-Nya agar tidak merusak lingkungan, diantaranya yang telah digambarkan dengan jelas dalam Qs. Arrum ayat 41. Tuntunan terpenting dalam agama Islam dalam hubungannya dengan aspek lingkungan adalah dengan menjaga keseimbangan lingkungan tanpa merusaknya. Allah menyukai orang yang selalu memperbaiki dan Allah tidak menyukai mereka yang suka berbuat kerusakan seperti yang terkadung dalam Qs Al Qashash ayat 77. Ayat diatas mengandung makna bahwa Allah SWT memerintahkan hamba-Nya untuk selalu menjaga lingkungan meliputi alam beserta isinya, untuk dipertahankan, dilindungi dan dipelihara keberadaannya. Sebab, konsumsi yang menimbulkan mafsadhat terhadap lingkungan di sekitarnya adalah bentuk dari tindakan yang di larang Allah SWT. Dengan demikian dalam Islam pengetahuan terhadap lingkungan serta sikap dalam pengambilan keputusan merupakan keharusan bagi setiap muslim. Sebab keputusan pembelian produk ramah lingkungan memberikan manfaat atau hubungan timbal balik yang positif terhadap lingkungan. Apabila generasi $\mathrm{Z}$ di kota Malang dalam melakukan pembelian produk dengan mempertimbangkan dampak yang akan ditimbulkannya, maka lingkungan akan tetap seimbang tanpa adanya kerusakan yang berlebihan.

Oleh sebab itu, sebagai seorang marketing pemasaran produk hijau sebaiknya terus melakukan pemasaran atas produk yang ramah lingkungan, dengan terus memberikan pengetahuan dan penyadaran akan pentingnya produk ramah lingkungan terhadap konsumen. Sebab kewajiban kita sebagai umat Islam atau makhluk ciptaan Allah SWT. sudah seharusnya kita ikut menjaga dan melestarikan lingkungan. Karena lingkungan merupakan bagian terpenting dalam kehidupan manusia, baik berkaitan dengan sumber daya manusia maupun alam yang berada di dalamnya. Dengan memberikan informasi yang mengandung manfaat bagi banyak orang akan produk ramah lingkungan hal ini sama dengan upaya penyelamatan lingkungan alam agar tidak cepat hilang dari keberadaan.

\section{Variabel Religiusitas dapat memperkuat hubungan antara lingkungan terhadap keputusan pembelian}

Salah alasan seseorang melakukan pembelian terhadap produk adalah karena religiusitas. Religiusitas di sini berfungsi sebagai faktor pendorong gaya hidup seorang konsumen, yang dapat mempengaruhi pilihan konsumen terhadap suatu produk. Religiusitas adalah sesuatu hal yang ada hubungannya 
Fani Firmansyah, Puji Endah Purnamasari, Muhammad Djakfar

dengan pengalaman, ritual agama dan juga kepercayaan. Dalam upaya pengambilan keputusan pembelian, seorang konsumen muslim menggunakan keyakinan di dalam hatinya untuk membeli produk yang ditawarkan produsen. Pembelian produk ramah lingkungan dipengaruhi oleh religiusitas yang dimiliki oleh seorang konsumen. Hasil penelitian ini didukung oleh Alam et al. (2011), Islam dan Chandrasekaran (2016), Bhuian dan Sujeet (2018) bahwa terdapat hubungan antara religiusitas dengan perilaku pembelian.

Dalam kehidupan bermasyarakat saat ini, religiusitas merupakan konsep penting yang tidak dapat dipisahkan dalam kehidupan sehari-hari. Alam et al. (2011) menganggap bahwa religiusitas adalah seperangkat keyakinan yang telah diajarkan sejak kecil dimana secara bertahap memiliki komitmen dengan agama. Aman et al. (2012) membuktikan bahwa variabel religiusitas akan mampu memberikan pengaruh cara hidup serta menentukan pilihan-pilihan yang mereka. Religiusitas dianggap akan mempengaruhi pilihan mereka dan perilaku mereka secara tidak langsung akan membentuk nilai-nilai dan sikap mereka (Islam \& Chandrasekaran, 2016).

Di dalam Islam strategi daur ulang merupakan salah satu bentuk aktivitas yang bermanfaat dan mengaplikasikan nilai-nilai syariat agama Islam. Sebab daur ulang merupakan upaya pencegahan pemborosan terhadap sumber daya, khususnya sumber daya alam . Pemborosan dalam aktivitas yang berhubungan dengan duniawi seperti konsumsi adalah suatu larangan dalam Islam seperti yang telah dijelaskan dalam firman-Nya Qs. Al-Isra ayat 26-27.

Ayat diatas mengandung makna bahwa keputusan terhadap pembelian produk ramah lingkungan merupakan sebuah keharusan dan kewajiban, hal ini dikarenakan konsumsi terhadap produk ramah lingkungan adalah konsumsi yang terhindar dari sikap boros. Allah tidak menyukai orang yang boros dalam konsumsi sehari-hari. Dalam aspek kehidupan sehari-hari, setiap Muslim diperintahkan untuk dapat menjaga lingkungannya. Alam dan bumi beserta segala isinya sebagai karunia Allah untuk memenuhi semua kebutuhan hidup manusia seperti makan, minum, pakaian, perumahan, dan lain sebagainya (Djakfar, 2012:186).

Dalam melakukan keputusan pembelian suatu produk hendaklah untuk memilih produk yang tidak merusak lingkungan. Sebab kerusakan lingkungan adalah dampak dari perbuatan tangan manusia yang tidak memikirkan akibatnya terhadap lingkungan. Dengan adanya religiusitas yang melekat pada diri seorang konsumen, maka keputusan seorang konsumen yang paham akan lingkungan akan mengambil keputusan untuk melakukan pembelian produk ramah lingkungan. 
Religiusitas, Lingkungan dan Pembelian Green Product...

Individu yang memiliki tingkat religiusitas yang tinggi harus selalu berkomitmen untuk selalu menjaga etika serta moral di dalam kehidupan, termasuk di dalamnya dalam berperilaku dalam pembelian suatu produk. Sebab Religiusitas merupakan budaya yang dapat membentuk perilaku seseorang (Kotler, 2000). Sehingga, religiusitas mampu memperkuat pengaruh variabel lingkungan dalam hubungannya dengan keputusan pembelian produk ramah lingkungan. Dengan demikian generasi $\mathrm{Z}$ di kota Malang akan terpengaruh oleh lingkungan dan akhirnya mempengaruhi generasi $\mathrm{Z}$ di kota Malang untuk melakukan pembelian terhadap produk ramah lingkungan (green product).

\section{Kesimpulan}

Kesimpulan dalam penelitian ini menunjukkan bahwa variabel lingkungan berpengaruh positif terhadap keputusan pembelian produk ramah lingkungan yang dipengaruhi oleh sikap serta pengetahuan terhadap lingkungan. Sehingga generasi Z di kota Malang terpengaruh oleh lingkungan dalam melakukan pembelian produk ramah lingkungan (green product). Religiusitas mampu memperkuat pengaruh variabel lingkungan terhadap keputusan pembelian produk ramah lingkungan disebabkan karena religiusitas berhubungan dengan nilai-nilai spiritual yang mempengaruhi tindakan seseorang dalam mengambil keputusan. Religiusitas sangat penting dalam kehidupan seseorang. Sehingga generasi $\mathrm{Z}$ yang memiliki tingkat religiusitas tinggi akan memikirkan lingkungan atas tindakan yang dilakukannya selama melakukan kegiatan pembelian. Dengan demikian generasi $\mathrm{Z}$ akan memilih produk ramah lingkungan (green product) agar lingkungan sekitar ia tempati aman dan terhindar dari kerusakan lingkungan.

\section{Daftar Pustaka}

Albayrak, Sevil, Ayse Yildiz, and Saime Erol. 2012. The Effect of Peer Bullying Education on Adolescents' Knowledge, Attitudes and Behaviors Towards Bullying. Procedia - Social and Behavioral Sciences 46:4620-25. Retrieved June 15, 2014 (http://linkinghub. elsevier. com / retrieve /pii/ S1877042812020447).

Ashary A, Muhammad A, Ahmad R. A. 2018. Pengetahuan dan Sikap Manusia Terhadap Isu Lingkungan. UNM Environmental Journals. Volume1 Nomor 1 April 2018 Hal. 53-58p-ISSN: 2598-6090dan e-ISSN: 25992902 
Fani Firmansyah, Puji Endah Purnamasari, Muhammad Djakfar

Alam, Syed Shah, Rohani Mohd and Badrul Hisham. 2011. Is religiosity an important determinant on Muslim consumer behaviour in Malaysia?. Journal of Islamic Marketing. Vol. 2 No. 1, 2011 pp. 83-96 q Emerald Group Publishing Limited. DOI 10.1108/17590831111115268

Ali, A., and Ahmad, I.. 2012. Environmental Friendly Products: Factors that Influence the Gre en Purchase Intentions of Pakistani Consumers. Pak. J. eng. Technol. Sci. 2 (1), pp: 84-117.

Aman, A.H.L, A. Harun, and Z. Hussein. 2012. The Influence of Environmental Knowledge and Concern on Green Purchase Intention the Role of Attitude as a Mediating Variable. British Journal of Arts and Social Sciences. 7 (2). pp: 145 - 167.

Bhuian, Shahid and Sujeet Kumar Sharma. 2017. Predicting Consumer ProEnvironmental Behavioral Intention: The Moderating Role of Religiosity. Review of International Business and Strategy. Vol. 27 Issue: 3, pp.352368. https://doi.org/10.1108/RIBS-03-2017-0022

Butler, S. (2013, Agustus 19). Ethical shopping growing in popularity, survey suggests. $\quad$ www.theguardian.com/business/2013/aug/19/ethicalshopping-growingpopularity-fairtrade.

Charter, M., Ottman, J., \& Polonsky, M. J. 2002. Marketing and Sustainability. BRASS.

Chen, T.B. dan Chai, L.T. 2010. Attitude towards the environment and green products. Management Science and Engineering. 4(2), 27-39.

D’Souza, Clar., Mehdi, T dan Peter, L. 2006. An Empirical Study on the Influence of Environmental Labels on Consumers. Corporate Communications: An International Journal. Vol. 11 No. 2. 2006. pp. 162-173.

Cronin, J., Smith, J., Gleim, M. R., Martinez, J.D., Ramirez, E. 2011. Green Marketing Strategies: An Examination of Stakeholders and the Opportunities They Present. Journal of the Academy of Marketing Science. 39 (1):158-174. DOI: 10.1007/s11747-010-0227-0

Djakfar, Muhammad. 2007. ETIKA BISNIS : Dalam Perspektif Islam. Malang: UIN Malang Press.

Djakfar, Muhammad. 2012. Etika Bisnis:Menangkap Spirit Ajaran Langit dan Pesan Moral Ajaran Bumi. Penebar Plus : Jakarta.

Eid, R and El-Gohary, H. 2014. Muslim Tourist Perceived Value in the Hospitality and Tourism Industry. Journal of Travel Research Fothcoming. DOI: $10.1177 / 0047287514532367$

Gurau, C. dan Ranchhod, A. 2005. International green marketing: A comparative study of British and Romanian firms. International Marketing Review. 22(5), 547-561. 
Religiusitas, Lingkungan dan Pembelian Green Product...

Hassan, S. H. 2014. The role of Islamic values on green purchase intention. Journal of Islamic Marketing. Vol. 5 Iss 3 pp. 379 - 395

Nugroho, M. A., Hariyanto, H., \& Suharini, E. 2017. Perilaku Peduli Lingkungan Siswa Sekolah Adiwiyata Perdesaan Dan Perkotaan Di Jawa Tengah Tahun 2016. Edu Geography. 5(2). 26-34

Islam, Tajamul and Uma Chandrasekaran. 2016. Effect of religiosity on ecologically conscious consumption behaviour. Journal of Islamic Marketing. Vol. 7 Issue: 4, pp.495-507

Ko, Seung Bong and Byoungho Jin. 2017. Predictors of purchase intention toward green apparel products: A cross-cultural investigation in the USA and China. Journal of Fashion Marketing and Management: An International Journal. Vol. 21 Issue: 1, pp.70-87. doi: 10.1108/JFMM-072014-0057

Kotler, P. 2000. Marketing management: Analysis, planning, implementation, and control. New Jersey: Prentice Hall.

Kotler, Philip and Gary Armstrong. 2008. Prinsip-prinsip Pemasaran. Edisi12. Jilid 1. Jakarta: Erlangga.

Maineri, T., Barnett, E., Valdero, T., Unipan, J. and Oskamp, S. 1997. Green buying: the influence of environmental concern on consumer buying. Journal of Social Psychology. Vol. 137 No. 2, pp. 189-204.

Muhamad, Nazlida., Vai Shiem Leong and Dick Mizerski. 2016. Consumer knowledge and religious rulings on products Young Muslim consumer's perspective. Journal of Islamic Marketing. Vol. 7 Iss 1 pp. 74 - 94

Ottman, J.A. Stafford E.\&R. Hartman.C.L. 2006 Green Marketing Myopia: Ways to Improve Consumer Appeal for Environmentally Preferable Products. Environment Volume 48, Number 5 pp: 22-36 Heldref Publication.

Oliver, R.L., (2010). A Cognitive Model of Antecedents and Consequences of Satisfaction Decisions. Journal of Marketing Research 27. pg. 460-469

Rahman, Mahfuzur., Mohamed Albaity and Billah Maru. 2016. The Role of Religiosity on the Relationship Between Materialism and Fashion Clothing Consumption Among Malaysian Generation Y Consumers. Springer Science. Business Media Dordrecht. Soc Indic Res. 132:757-783. DOI 10.1007/s11205-016-1310-9.

Rhasid, N. R. N.A. 2009. A wareness of Eco-label in Malaysia's Green Marketing Initiative.International Journal of Bussines and Management. 4 (8). pp: 132-133.

Saputra, Lyndon. 2013. Pengantar Kebutuhan Dasar Manusia. Jakarta: Binarupa Aksara 
Fani Firmansyah, Puji Endah Purnamasari, Muhammad Djakfar

Shamsadami P., Chon-Lin, G., and Richmond, D. 1993. Exploring Green Consumers in an Oriental Culture: Role of Personal and Marketing Mix. Advances in Consumer Research. 20. 488-493. Jurnal. http://www.acrwebsite.org

Shimp, Terence A. 2000. Periklanan Promosi Aspek Tambahan Komunikasi Pemasaran Terpadu.Terjemahan oleh : Revyani Sjahrial, S.E. dan Dyah Anikasari,S.Sos.2003. Jakarta: Erlangga.

Suki, Norazah Mohd. 2013. Students' Demand for Smartphones: Structural Relationships of Product Features, Brand Name, Product Price and Social Influence. Campus-Wide Information Systems. Vol. 30 No. 4.

Suki, Norazah Mohd and Norbayah Mohd Suki. 2015. Does religion influence consumers' green food consumption? Some insights from Malaysia. Journal of Consumer Marketing. Vol. 32 Iss 7 pp. 551 - 563

Wasik, J.F. 1996. Green marketing and management: A global perspective. Cambridge, Mass: Blackwell Publishers Inc. 